Technological University Dublin

DÜBLIN

ARROW@TU Dublin

2014-03-11

\title{
A Cavity-Backed Spiral Slot Antenna with Wide Axial Ratio Beamwidth for GPS System
}

Xiulong Bao

Technological University Dublin, xiulong.bao@tudublin.ie

Max Ammann

Technological University Dublin, max.ammann@tudublin.ie

Follow this and additional works at: https://arrow.tudublin.ie/ahfrcart

Part of the Systems and Communications Commons

\section{Recommended Citation}

Bao, X. \& Ammann, M. (2014) A Cavity-Backed Spiral Slot Antenna with Wide Axial Ratio Beamwidth for GPS System. Microwave and Optical Technology Letters, Vol. 56, Issue 5, May. doi:10.1002/mop.28255

This Article is brought to you for free and open access by the Antenna \& High Frequency Research Centre at ARROW@TU Dublin. It has been accepted for inclusion in Articles by an authorized administrator of ARROW@TU Dublin. For more information, please contact arrow.admin@tudublin.ie, aisling.coyne@tudublin.ie, gerard.connolly@tudublin.ie.

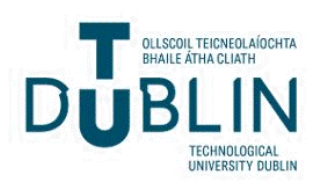




\title{
A Cavity-Backed Spiral Slot Antenna with Wide Axial Ratio Beamwidth for GPS System
}

\author{
X. L. Bao and M. J. Ammann
}

Abstract---A monofilar spiral slot antenna with a cavity-backed reflector is described. presented, which can achieve the performance of the wide Axial Ratio beamwave for Global Positioning System GPS system. It comprises an arrangement of a single printed spiral slots fed by a $50 \Omega$ microstrip line. By using cavity-backed covering the slot structure, a wide axial ratio beamwidth performance is achieved in the GPS L1 frequency. The angle with less than $3 \mathrm{~dB}$ axial ratio at $1.575 \mathrm{GHz}$ in the YoZ plane is about 215 degree. The measured results show that the HPWB beamwidths at $1.575 \mathrm{GHz}$ are 100 degree in the YoZ plane, respectively. The peak gain is $5.5 \mathrm{dBic}$.

Index Terms - Spiral slot antenna, circular polarization, GPS system, wide beamwidth,

\section{INTRODUCTION}

In recent decades, circularly-polarized antennas have become more attractive for wireless communication and sensor system applications due to the mitigation of multipath propagation effects as well as reduced antenna orientation constraints. In GPS applications, it is important to have a wide beamwidth in the circularly polarized radiation pattern, in order to achieve a full sky view. To improve the beamwidth for printed patch antennas, some technologies have been reported in the literature [1-6]. One method is to shape the groundplane to improve beamwidth, such as a 3D square ground plane which obtained over $113^{\circ}$ [1], a pyramidal groundplane and the partially enclosed flat conducting wall [2] were employed to provide a $130^{\circ}$ axial ratio beamwidth, and a folded and drooped groundplane was used to realize over $110^{\circ}$ beamwidth [3]. Another method is to extend the substrate to achieve wide dual band beamwidth [4]. Additionally, a combined structure of horizontal bow-tie patches and vertical dipoles was alos shown to widen the beamwidth [5]. Furthermore, in order to achieve directional radiation patterns and enhance the antenna gain, microstrip-fed slot antennas with a cavity reflector were reported [6]. But there is no report of wide beamwidth circularly polarized cavity-backed slot antenna the open literature.

In this paper, a monofilar spiral slot antenna is proposed, which has a cavity-backed reflector to suppress the rearward radiation, providing wide $3 \mathrm{~dB}$ axial ratio beamwidths in both principle planes.

\section{ANTENNA GEOMETRY AND CIRCULAR POLARIZATION MECHANICSM}

A single spiral slot antenna with a cavity-backed reflector is shown in Figure 1 with the coordinate system and dimensional parameters. The outer and inner radius sequentially increases with movement of the origin point each quarter turn. The starting values are outer radius $R_{l}$ and origin $O_{l}$. The second quadrant has outer radius $R_{2}$ and origin $O_{2}$. The $3^{\text {rd }}, 4^{\text {th }}$ and $5^{\text {th }}$ quadrants have radii $R_{3}, R_{4}$ and $R_{5}$ with origins $O_{3} O_{4}$ and $O_{1}$, respectively. The slot maintains the same width $W_{l}$. The two endpoints of the spiral slot have extended lengths $L_{1}$ and $L_{2}$. In order to improve matching for both bands, the microstrip feedline width is stepped using lengths $L_{s l}, L_{s 2}$ and widths $W_{s 1}$ and $W_{s 2}$ as shown in Figure 1. The slot perimeter length corresponds approximately to one guided wavelengths for the operation frequency.

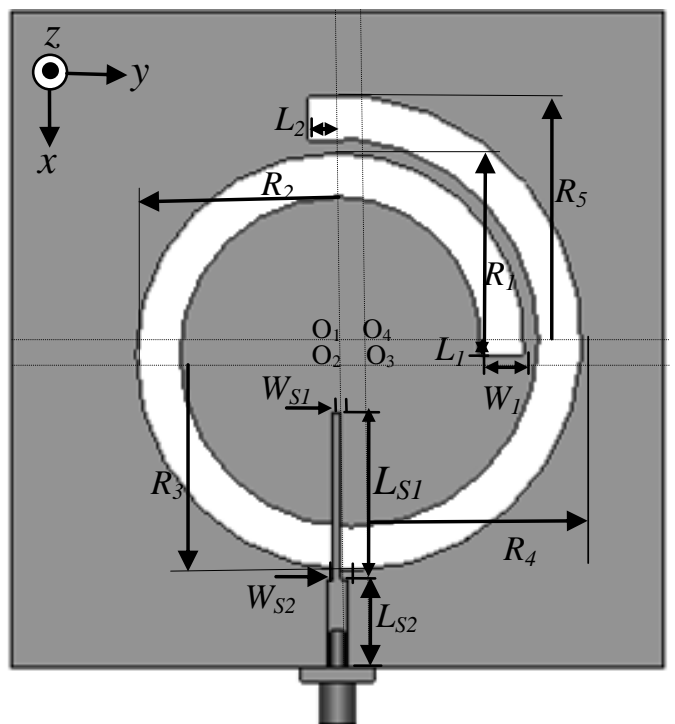

(a)

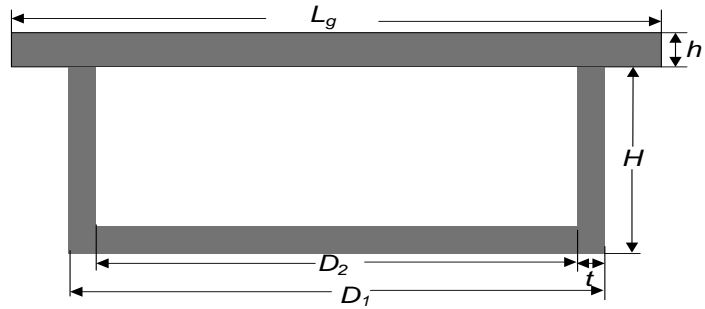

(b)

Figure 1 (a) Configuration of the antenna showing spiral slot on the rear of the board and fed by microstrip line on the near side, (b) The profile of the proposed antenna with cavity-backed reflector

In order to investigate the circular-polarization mechanism, the current distributions at $1.575 \mathrm{GHz}$ for four phase values of $0^{\circ}$, $45^{\circ}, 90^{\circ}$ and $135^{\circ}$ are shown in Figure 2 . It is found that the magnetic current wave travels in an anti-clockwise fashion when viewed from the $+Z$ direction leading to the radiation of a right-hand circularly polarized wave. Thus the polarization sense for the low frequency range is RHCP. 


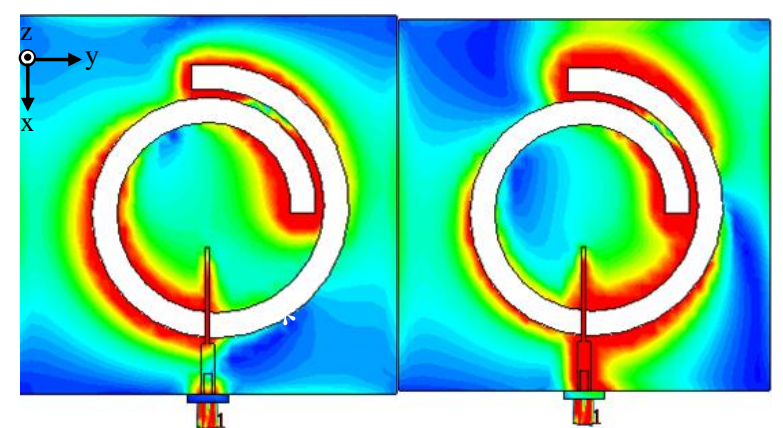

(a) $0^{\circ}$

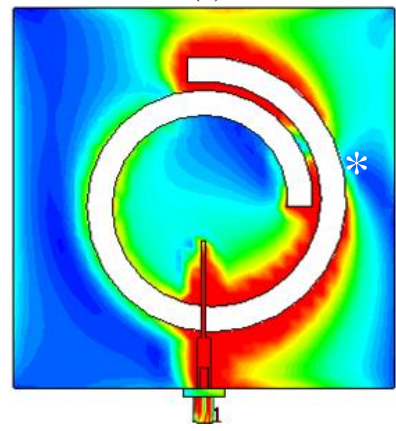

(b) $45^{\circ}$

(c) $90^{\circ}$

(d) $135^{\circ}$

Figure 2. Surface current distributions at $1.575 \mathrm{GHz}$ showing RHCP when viewed from the $+\mathrm{Z}$ direction

\section{ANALYSIS AND DESIGN OF THE PROPOSED ANTENNA}

The single spiral slot is printed on the substrate with $\varepsilon_{\mathrm{r}}=3.5$, $\tan \delta=0.0018$ and of thickness $=1.57 \mathrm{~mm}$. The groundplane size was chosen to be $90 \mathrm{~mm} \times 90 \mathrm{~mm}$ which is approximately a half of a free space wavelength at the lowest operating frequency. The $50 \Omega$ microstrip feedline $\left(W_{s 2}=3.0 \mathrm{~mm}\right)$ is stepped to $W_{s l}=1 \mathrm{~mm}(95 \Omega)$ for good matching to the higher impedance slot. In order to obtain circular polarization, the slot radius is increased to provide the spiral geometry. The origin $\mathrm{O}_{1}$ is positioned centrally in the board and an origin offset of $\mathrm{O}_{1} \mathrm{O}_{2}$ $=\mathrm{O}_{3} \mathrm{O}_{4}=2 \mathrm{~mm}$ is used. The starting slot radius $R_{l}$ is chosen to be approximately $1 / 8$ of a guided wavelength for the lowest frequency. Subsequent radii increase by $2 \mathrm{~mm}$ per quarter-circle which was found to provide best axial-ratio and matching.

For the spiral slot antenna, the radiation patterns are dependent on the length of the slot perimeter [7]. Usually, spiral slot antennas radiate axially when the length of the perimeter is between the one and two guided wavelengths. However, it will radiate a titled beam when the perimeters are greater than two guided wavelengths. In this case, the slot perimeter length approximates one guided wavelength to provide an axial beam. In order to adjust the centre frequency and get the appropriate frequency bands for GPS system, some parameters of antenna, such as the height and diameter of the cavity-backed reflector and the microstrip feedline length $L_{\mathrm{s} 1}$ are discussed in details.

The parametric study is made using the time domain solver in CST MWS. Other parameters are fixed as follows: $W_{s l}=1.0$ $\mathrm{mm}, W_{s 2}=3.0 \mathrm{~mm}, L_{s 2}=12.0 \mathrm{~mm}, R_{1}=26.0 \mathrm{~mm}, R_{2}=28.0 \mathrm{~mm}$, $R_{3}=30.0 \mathrm{~mm}, R_{4}=32.0 \mathrm{~mm}, R_{5}=34.0 \mathrm{~mm}, \mathrm{O}_{1} \mathrm{O}_{2}=\mathrm{O}_{2} \mathrm{O}_{3}=$ $\mathrm{O}_{3} \mathrm{O}_{4}=\mathrm{O}_{1} \mathrm{O}_{4}=2.0 \mathrm{~mm}, L_{l}=2 \mathrm{~mm}, L_{2}=4 \mathrm{~mm}, W_{l}=6 \mathrm{~mm}, L_{g}$ $=90 \mathrm{~mm}, \mathrm{~h}=1.57 \mathrm{~mm}, \mathrm{t}=3 \mathrm{~mm}$.
The height of the cavity-backed reflector have affected on the $S_{11}$ and axial ratio curves. Figure 3 and Figure 4 show the centre frequency to increase as the height of the cavity-backed reflector decreases.

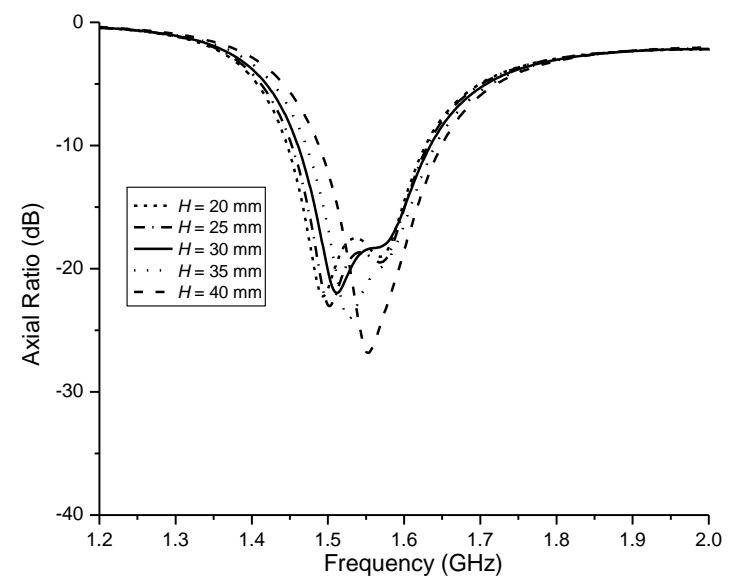

Figure 3. The simulated $S_{11}$ for different heights of the cavitybacked reflector $\left(L_{S l}=21 \mathrm{~mm}, D_{l}=38 \mathrm{~mm}\right)$

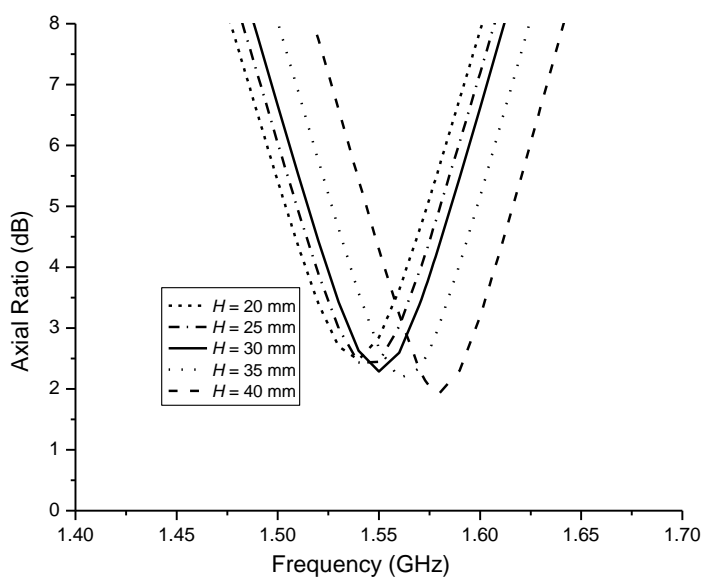

Figure 4. The simulated axial ratio for different heights of the cavitybacked reflector $\left(L_{S 1}=21 \mathrm{~mm}, D_{l}=38 \mathrm{~mm}\right)$

Figure 5 illustrates the $S_{11}$ for different values of microstrip feedline coupling length $L_{s l}$. By increasing the coupling length, the frequency of the lower band is shifted downwards. The sensitivity of matching to the line length is seen in Figure 5. But for axial ratio curves, there is little effect with different microstrip feedline length $L_{S l}$, as shown in Figure 6.

Figure 7 and Figure 8 display the $S_{11}$ and axial ratio for different diameters of cavity-backed reflector, respectively. It is found that the working frequencies is shifted downwards as the diameter of the cavity-backed reflector is increased. 


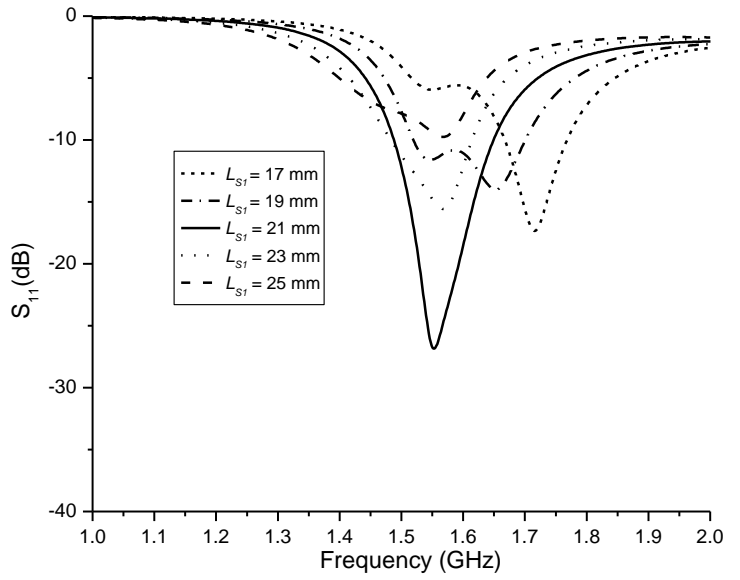

Figure 5. The simulated $S_{11}$ for different $L_{S l}\left(H=30 \mathrm{~mm}, D_{l}=38\right.$ $\mathrm{mm})$

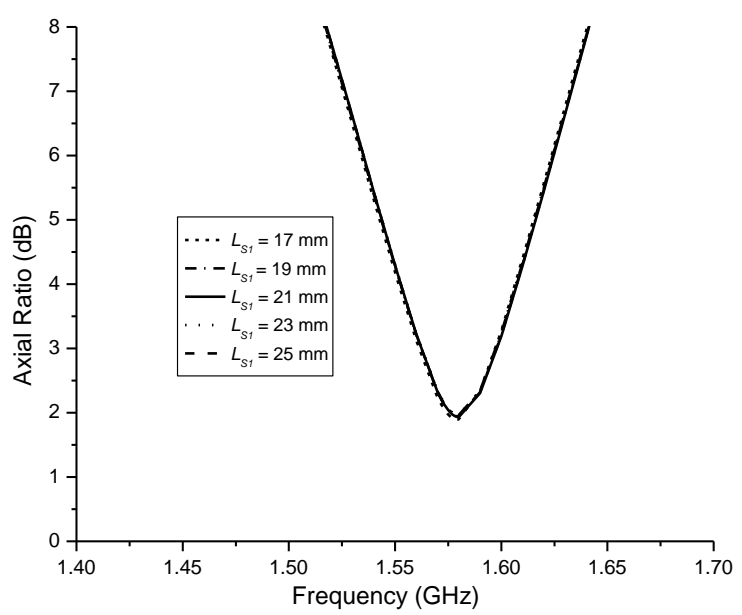

Figure 6. The simulated axial ratio for different $L_{S l}\left(H=30 \mathrm{~mm}, D_{l}\right.$ $=38 \mathrm{~mm}$ )

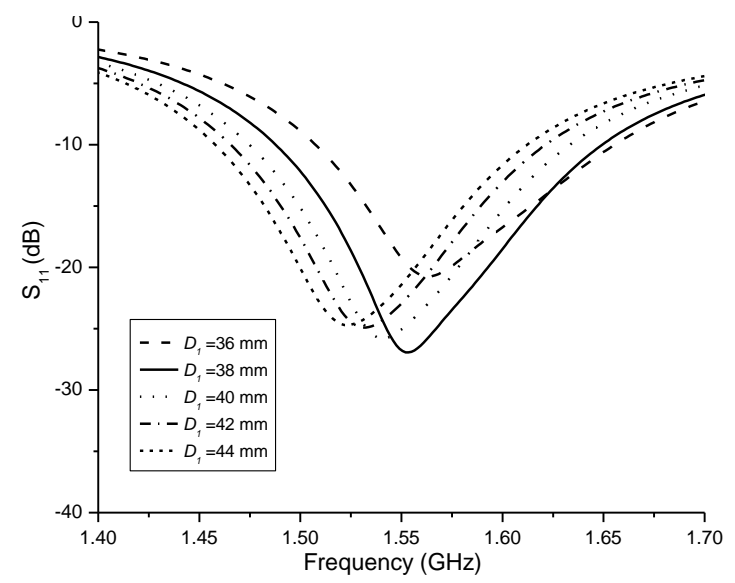

Figure 7. The simulated $S_{11}$ for different diameters of the cavity-backed reflector $\left(L_{S I}=21 \mathrm{~mm}, H=30 \mathrm{~mm}\right)$

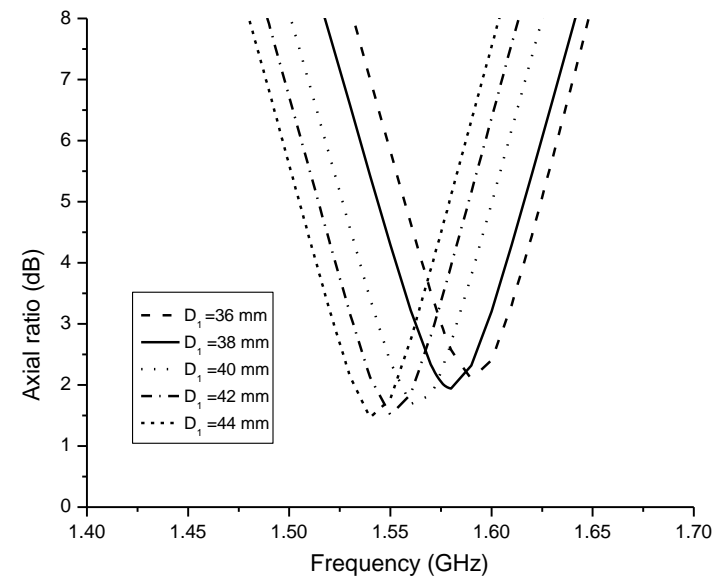

Figure 8. The simulated axial ratio for different diameters of the cavity-backed reflector $\left(H=30 \mathrm{~mm}, L_{S I}=21 \mathrm{~mm}\right)$

\section{NUMERICAL RESULTS}

The proposed spiral slot antenna was prototyped and tested. The selected dimensions of the antenna parameters are listed as: $W_{s 1}=1.0 \mathrm{~mm}, W_{s 2}=3.0 \mathrm{~mm}, \mathrm{~L}_{\mathrm{s} 1}=21.0 \mathrm{~mm}, L_{s 2}=12.0 \mathrm{~mm}$, $R_{I}=26.0 \mathrm{~mm}, R_{2}=28.0 \mathrm{~mm}, R_{3}=30.0 \mathrm{~mm}, R_{4}=32.0 \mathrm{~mm}, R_{5}=$ $34.0 \mathrm{~mm}, \mathrm{O}_{1} \mathrm{O}_{2}=\mathrm{O}_{2} \mathrm{O}_{3}=\mathrm{O}_{3} \mathrm{O}_{4}=\mathrm{O}_{1} \mathrm{O}_{4}=2.0 \mathrm{~mm}, L_{1}=2 \mathrm{~mm}$, $L_{2}=4 \mathrm{~mm}, W_{l}=6 \mathrm{~mm}, L_{g}=90 \mathrm{~mm}, H=30 \mathrm{~mm}, h=1.57 \mathrm{~mm}, t$ $=3 \mathrm{~mm}, D_{l}=38 \mathrm{~mm}$. Figure 9 and Figure 10 show the simulated and measured $S_{11}$ and axial ratio, respectively. The measured results show the $S_{11}$ to be less than $-10 \mathrm{~dB}$ for approx. $120 \mathrm{MHz}$ from $1.50 \mathrm{GHz}$ to $1.62 \mathrm{GHz}$. The $3 \mathrm{~dB}$ axial ratio bandwidth is $68 \mathrm{MHz}(4.3 \%)(1.541 \mathrm{GHz}$ to $1.609 \mathrm{GHz})$. The $3 \mathrm{~dB}$ axial ratio beamwidths are shown in Figure 11 at 1.570 $\mathrm{GHz}, 1.575 \mathrm{GHz}, 1.580 \mathrm{GHz}$, respectively. It is noted that axial ratio is less than $3 \mathrm{~dB}$ for $215^{\circ}$ in the YoZ plane and $100^{\circ}$ in the XoZ plane at $1.575 \mathrm{GHz}$, as shown in Figure 12.

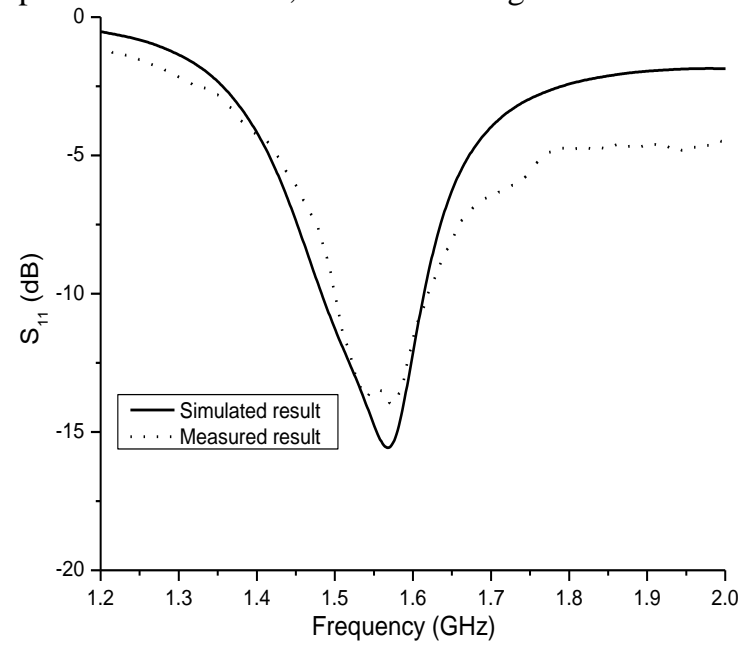

Figure 9. Comparison of the simulated and measured $S_{11}$ 


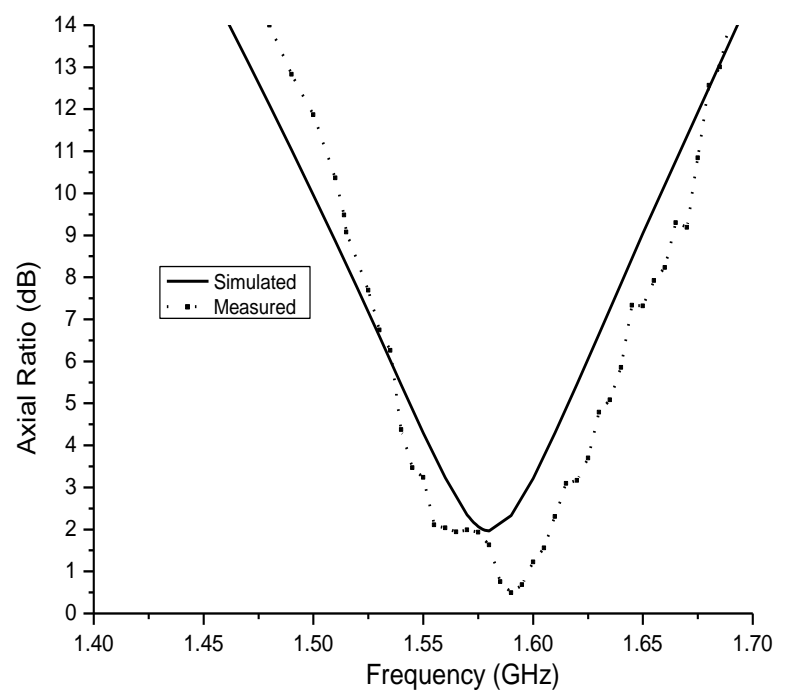

Figure 10. Comparison of the simulated and measured axial ratio

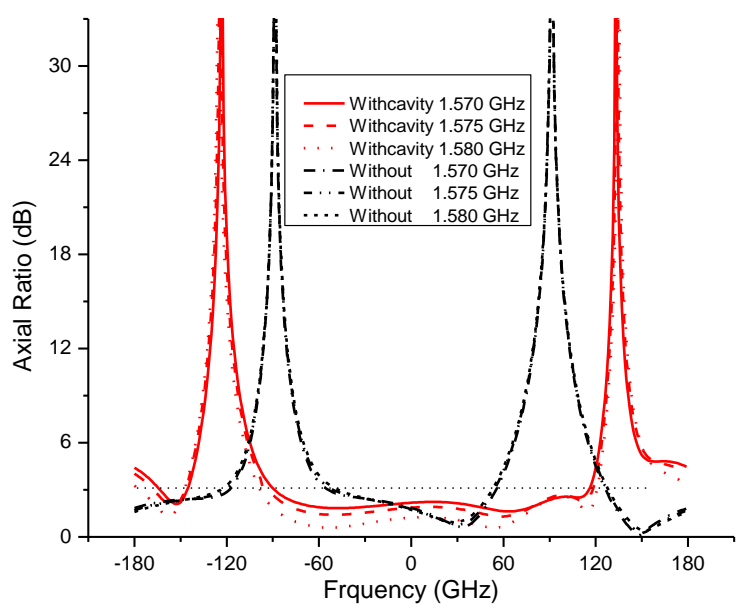

Figure 11. Simulated axial ratio in the YoZ plane with cavity reflector and without cavity reflector

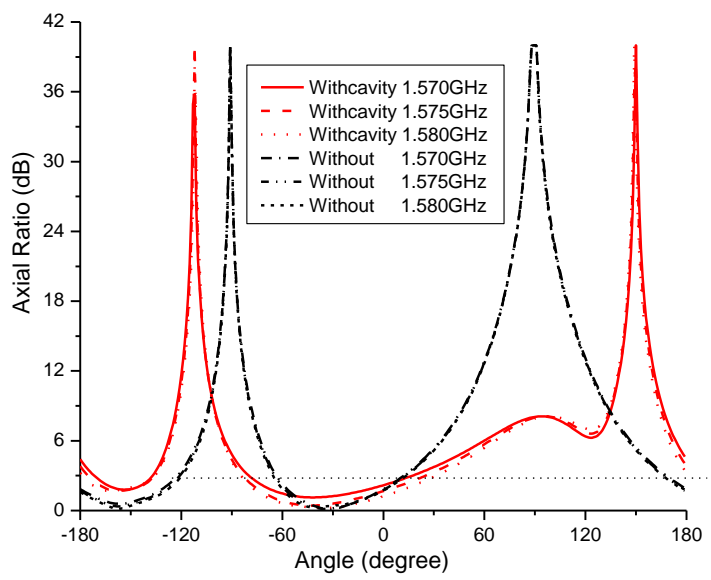

Figure 12. Simulated axial ratio in the XoZ plane with cavity reflector and without cavity reflector

Figure 13 and Figure 14 show the measured and simulated radiation patterns at $1.575 \mathrm{GHz}$. It is found that there are about $215^{\circ}$ and $100^{\circ}$ half power beamwidth (HPBW) in the YoZ plane and $\mathrm{XoZ}$ plane, respectively. The measured peak gain at 1.575 $\mathrm{GHz}$ is $5.5 \mathrm{dBic}$.

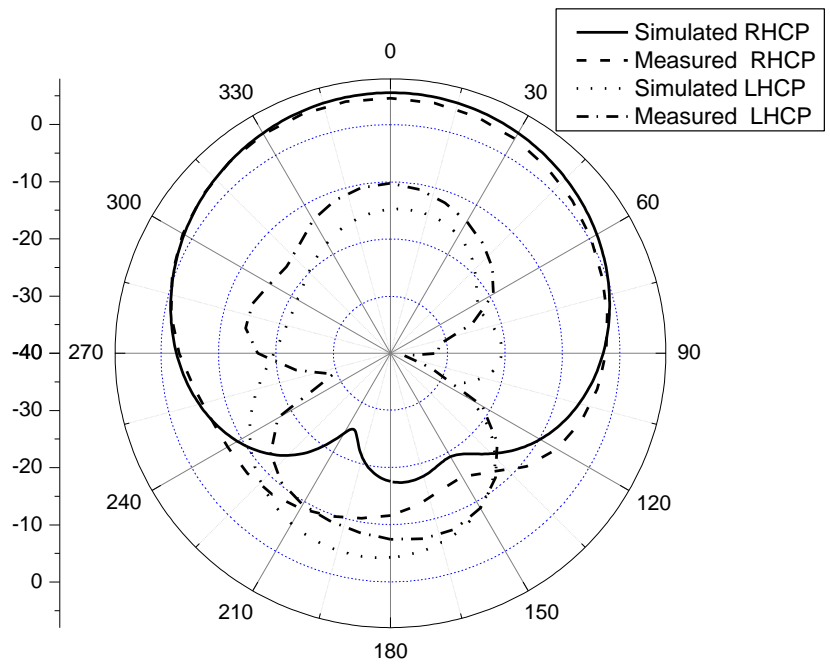

Figure 13. Simulated and measured radiation patterns at 1.575 $\mathrm{GHz}$ in the YoZ plane

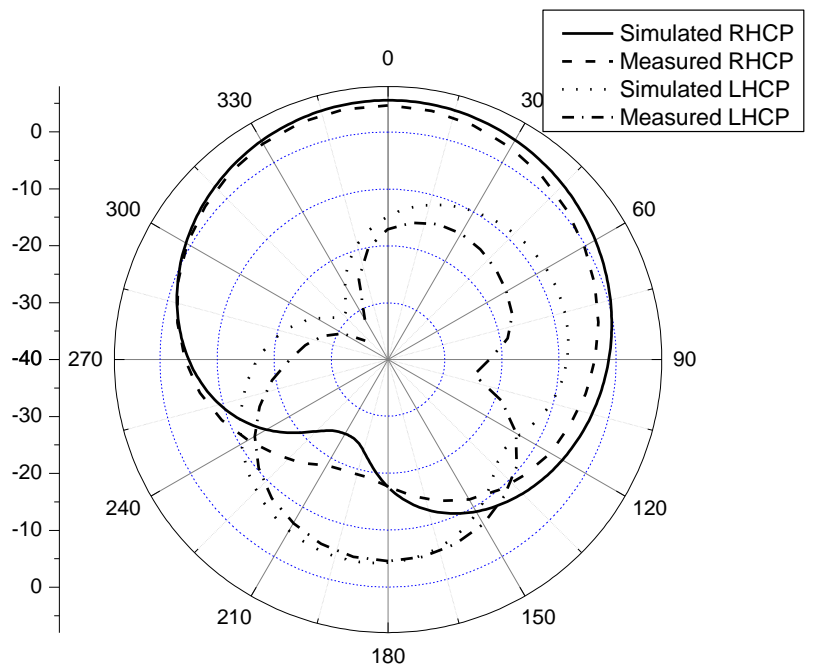

Figure 14. Simulated and measured radiation patterns at 1.575 $\mathrm{GHz}$ in the $\mathrm{XoZ}$ plane

\section{CONCLUSION}

A novel circularly-polarized spiral slot antenna for GPS system was modeled, fabricated and tested. The proposed antenna is composed of a spiral slot cavity-backed a reflector and fed by a $50 \Omega$ microstrip line. The proposed antenna can achieve righthand circular polarization with an axial ratio beamwidth of $215^{\circ}$. Its peak gain is $5.5 \mathrm{dBic}$ at $1.575 \mathrm{GHz}$.

\section{ACKNOWLEDGMENT}

This publication has emanated from research conducted with the financial support of Science Foundation Ireland under Grant Number 09/SIRG/I1644. 


\section{REFERENCES}

[1]. L. Tang, J. Y. Chiou, and K. L. Wong, Beamwidth Enhancement of a Circularly Polarized Microstrip Antenna Mounted on a ThreeDimensional Ground Structure, Microwave and Optical Technology Letters, Vol. 32, No. 1, 2002, pp. 149 -153.

[2]. W. Su, S. K. Huang, and C.H. Lee, CP microstrip Antenna with Wide Beamwidth for GPS Band Application, Electronics Letters, Vol. 43, No. 20, pp.

H. M. Al-Rizzo, K. G. Clark, J. M. Tranquilla, R. A. Adada, et al., Enhanced Low-Angle GPS Coverage Using Solid and Annular Microstrip Antennas on Folded and Drooped Ground Planes, IEEE Transactions on Antennas and Propagation, Vol. 57, No. 11, 2009, pp. 3668-3672.

[4]. X. L. Bao, M. J. Ammann, Dual-Frequency Dual Circularly-Polarized Patch Antenna with Wide Beamwidth, Electronic Letters, Vol. 44, No. 21, 2008, pp. 1233-1234.

[5]. K. M. Mak, and K. M. Luk, A Circularly Polarized Antenna With Wide Axial Ratio Beamwidth, IEEE Transactions on Antennas and Propagation, Vol. 57, No. 10, 2009, pp.3309-3312.

[6]. Q. Li, and Z. X. Shen, An Inverted Microstrip-Fed Cavity-Backed Slot Antenna for Circular Polarization, IEEE Antennas and Wireless Propagation Letters, Vol. 1, 2002, pp.190-192.

[7]. H. Nakano, J. Eto, Y. Okabe, and J. Yamauchi, Tilted- and Axial-Beam Formation by a Single-Arm Rectangular Spiral Antenna With Compact Dielectric Substrate and Conducting Plane, IEEE Transactions on Antennas and Propagation, Vol. 50, No. 1, 2002, pp. 17- 23. 